\title{
Argument Strength, the Toulmin Model, and Ampliative Probability
}

\author{
JAMES B. Freeman
}

\author{
Hunter College of The City \\ University of New York
}

\begin{abstract}
We argue that Cohen's concept of inductive or ampliative probability facilitates proper explication of sufficient strength for non-demonstrative arguments conforming to the Toulmin model. The data and claims of such arguments are singular statements. We may epistemically classify the warrants of such arguments as empirical (either physical or personal), institutional, or evaluative. Backing evidence and rebutting considerations vary with the epistemic type of warrant, but in each case the notion of ampliative probability for arguments with warrants of that type can be characterized. We may then use ampliative probability to define sufficient strength and related notions for Toulmin arguments.
\end{abstract}

Résumé: On argumente que le concept de la probabilité inductive ou ampliative de Cohen aide à l'explication proper de la force suffisante pour des arguments non-démonstratifs qui conforment au modèle Toulmin. Les données et les réclamations de tels arguments sont des énoncés singuliers. On peut classer épistemiquement les mandates de tels arguments comme impirique (ou matériel ou personnel), institutional, ou évaluatif. L'évidence qui renforce et les facteurs de réfutation correspondent au genre de mandat, mais en toute hypothèse on peut characteriser l'idée de la probabilité ampliative pour des arguments avec les mandats de ce type. Ensuite on peut se servir de la probabilité ampliative pour définir la force suffisante et les notions connexes des arguments Toulmin.

Keywords: L.J. Cohen, Toulmin model, ampliative probability, inductive support, inductive probability, warrant, backing, rebuttal, canonical test

\section{The Problem}

Many within informal logic hold that to be logically good, the premises of an argument must constitute grounds adequate for the conclusion. This criterion is also expressed by saying that the premises must support the conclusion with sufficient strength or weight, sufficient that is to transfer the acceptability of the premises to the conclusion. But "strength," "weight" are obviously metaphorical. What does argument strength or weight of premises mean literally? How, in a given case, may one determine degree of strength, and how much strength is necessary to be sufficient? These are open questions. To be sure, support is 
sufficient if the premises deductively entail the conclusion. To be sure also, for non-demonstrative arguments, many textbooks offer a "popular" answer-the premises must render the conclusion probable. More specifically, the probability of the conclusion, given the premises, must be sufficiently high.

But what is this relation? There is not even terminological agreement in the literature. Plantinga (1993, p. 139) calls it epistemic conditional probability. Skyrms (2000, p. 21) calls it inductive probability, using "epistemic probability" for a distinct notion, the inductive probability of a statement given one's stock of relevant knowledge. The very use of "inductive" may be contentious. Some, Govier (1987, pp. 37-54) in particular, believe there are various types of non-demonstrative argument, inductive being only one. Following Cohen in (1989), we propose to call the relation "ampliative probability." Inductive probability suggests being inductive in the stereotypical sense of being based on generalizations supported by evidence concerning particular observed instances. Ampliative induction "extrapolates beyond the existing data," (Cohen 1989, p. 1) the hallmark of any non-demonstrative argument, and may be applied to non-empirical issues of 'ought' in addition to 'is.' However, Plantinga has succinctly characterized the problem: "What is the relation between a pair of propositions $A$ and $B$ when the epistemic conditional probability of $A$ on $B$ is high? [In asking the question of an argument, we may clearly let $B$ be the conjunction of the premises.] What kind of account or analysis can we give of this relation? What makes it the case that $\mathrm{P}(A / B)$ is high?" (1993. p. 139)

Let us designate the ampliative probability of $C$ with respect to $P$ by $\operatorname{Pr}_{\mathrm{A}}(C /$ $P)$. Where $P$ is the conjunction of the premises of a non-demonstrative argument, are we thus saying that the relation denoted by $\operatorname{Pr}_{\mathrm{A}}(C / P)$, and thus the concepts of argument strength or weight, satisfy the axioms of the probability calculus? In (1977) and (1989), Cohen has raised significant objections to this claim. Probability on the standard theory satisfies the complementational principle: $\mathrm{P}(\sim B / A)=1$ $\mathrm{P}(B / A)$. Where $D$ is the data that five voters interviewed support Jones and $C$ the claim that the next voter to be interviewed will support Jones, assuming a voting population of any significant size, the strength of the argument from $D$ to $C$ is intuitively weak; $\operatorname{Pr}_{\mathrm{A}}(C / D)$ is low. But it does not follow that $\operatorname{Pr}_{\mathrm{A}}(\sim C / D)$ is high. (If anything, it is lower.) The data simply do not give us strong reason to accept either the conclusion or its negation.

It seems that the multiplicative principle for conjunction may also be counterexampled. In (1989, p. 19), Cohen asks us to "suppose an art historian declares two pictures to be genuine Vermeers." Let $\mathrm{p}_{1}, \mathrm{p}_{2}$ denote these two paintings respectively. Let $P_{1}$ abbreviate the statement "Painting $\mathrm{p}_{1}$ is a genuine Vermeer" and similarly for $P_{2}$ Let $V_{1}$ abbreviate the statement "The art historian vouches for $P_{1}$ " and similarly for $V_{2}$. Then consider the argument:

$$
\therefore \frac{V_{1} \& V_{2}}{P_{1} \& P_{2}}
$$

Let us assume that the art historian's examining and rendering an opinion on $\mathrm{p}_{1}$ 
does not affect his judgment on $\mathrm{p}_{2}$ or vice versa. It would seem then that $V_{2}$ is not relevant to $P_{1}$ and $V_{1}$ is not relevant to $P_{2}$. Suppose the art historian is highly respected and his judgment thus highly reliable. Suppose we want to say then that $\operatorname{Pr}_{\mathrm{A}}\left(P_{1} / V_{1}\right)$ is high, e.g. $=.9$, likewise for $\operatorname{Pr}_{\mathrm{A}}\left(P_{2} / V_{2}\right)$ Hence $\operatorname{Pr}_{\mathrm{A}}\left(P_{1} / V_{1} \& V_{2}\right)=.9$ $=\operatorname{Pr}_{\mathrm{A}}\left(P_{2} / V_{1} \& V_{2}\right)$. But does it follow that $\operatorname{Pr}_{\mathrm{A}}\left(P_{1} \& P_{2} / V_{1} \& V_{2}\right)=.9 \times .9=.81$ ? Does it follow that the more paintings an expert vouches for, the weaker the argument? Why, having examined both paintings, is the weight, strength, probative force of the expert's voucher thus weakened? Should the multiplicative principle hold, then, should the expert vouch for three paintings, the strength of his voucher would be weaker yet. If he vouched for seven, $\operatorname{Pr}_{\mathrm{A}}\left(P_{1} \& P_{2} \& \ldots \& P_{7} / V_{1} \& V_{2} \&\right.$ $\left.\ldots \& V_{7}\right)=.4783$, less likely than not. But is this true? Cohen comments, "The warranty for the conjunction seems no less reputable, and no less thoroughly researched, than for either of the conjuncts.... Of course, the chance of both pictures' being genuine may well be a lot less than the chance of just one's being genuine. But is the credibility of their genuineness to be judged in terms of such chances...or in terms of the reputation of the author of the warranties that have been given you?" (Cohen, 1989, pp. 19-20)

Cohen has proposed an alternative account of ampliative probability. Is this account more suitable to explicate the notion of strength, weight, or ground adequacy, for non-demonstrative arguments? This is a huge question, since the class of non-demonstrative arguments is very diverse. But there is an intriguing way to cut down this question to approach a partial answer. In (1977), Cohen offers ampliative probability as an account of strength for a particular class of non-demonstrative arguments, including arguments frequently found in judicial contexts. In (1958), Toulmin proposes a jurisprudential model or analogy as a general understanding of argument. The conjunction of Toulmin and Cohen as seeing jurisprudential or judicial arguments as somehow typifying a wider, even generic class of arguments is striking. To what extent can Cohen's concept of inductive probability be applied to assessing strength of arguments properly understood according to Toulmin's jurisprudential model?

\section{Toulmin Arguments and Warrants}

Although Toulmin proposed his model as a general account of the layout of arguments, there is implicit in his discussion a feature which arguably constitutes a significant limitation. In presenting his layout, all the examples of claims are singular statements:

Harry's hair is not black.

Petersen will not be a Roman Catholic.

Wilkinson has committed an offence against the Road Traffic Acts.

Harry is a British subject. (1958, pp. 97, 99)

Likewise, the data statements are all singular: 
Harry's hair is red.

Petersen is a Swede.

Wilkinson was timed driving 45 m.p.h. in a built-up area.

Harry was born in Bermuda.

Toulmin's discussion considers no examples where claim or data are generalizations. If one accepts that universal generalizations are legitimate statements, which may be argued from or for, that such statements appear neither as claims or data in Toulmin's model constitutes a significant limitation. ${ }^{1}$ Thus, the class of arguments to which the Toulmin model may be applied is apparently restricted to arguments from singular premises to singular conclusions. But this is not an insignificant class of arguments. Let us refer to the non-demonstrative members of this class of arguments as Toulmin arguments. Such arguments then proceed from singular data premises to singular conclusions or claims. The warrants of such arguments are less than universal, subject to conditions of rebuttal, and may be backed in various ways.

As we shall develop in this paper, the combination of backing and rebuttals for a given warrant determine its degree of ampliative support, which then constitutes the strength or ampliative probability of the corresponding argument. We now come to a crucial point. As we have indicated in (2005b), although Toulmin saw arguments belonging to fields and criteria for evaluating arguments as field dependent, determined by what is recognized as good arguments by practitioners within that field, we may classify the warrants of arguments epistemically. The faculties or belief-generating mechanisms enabling one to grasp the connection indicated by a warrant in the first place and to identify the rebuttals and backing bearing on what Toulmin would call the warrant's authority and currency constitute different factors determining the strength of the warrant. We contend that determining the strength of non-demonstrative Toulmin arguments involves taking account of these epistemic factors and that this strength can be understood through Cohen's account of ampliative probability.

In (2005b), we distinguished three types of contingent warrants-empirical, institutional, and evaluative. Empirical warrants, such as

Given that $x$ is a member of a colony of bees

One may take it that $\quad x$ will return repeatedly to a blue colored food source concern connections recognized through observation. These connections can not only be between overtly observable events or conditions, as in our example, but may concern connections between intentions and behavior.

Given that

One may take it that

Given that

One may take it that $x$ intends to return the book

$x$ will take some action causing the book's return $x$ has mailed the letter $x$ wants the addressee to receive it.

The former we call empirical physical warrants, while the latter are empirical personal warrants. Empirical warrants are supported "from below," by observation 
of particular instances. Institutional warrants by contrast are supported from above, through our understanding of constitutive principles. We understand "institution" in Searle's sense as a system of constitutive rules $(1969$, p. 51$)$, where such rules "do not merely regulate, they create or define new forms of behavior" (1969, p. 33). The paradigm cases of institutional warrants are legal warrants. For example,

Given that $\quad x$ is a contract signed by both parties

We may take it that $\quad x$ is valid

Toulmin's perhaps most classic example illustrates a legal warrant:

Given that $\quad x$ was born in Bermuda

We may take it that $\quad x$ is a British subject

Clearly, one would not observe to see whether contracts signed by both parties are valid (whatever observing validity might mean). Rather, one would consult the relevant section of contract law. Our reading, involving not simply observation but understanding, of that section would constitute evidence backing the warrant. Likewise, an empirical survey of those born in Bermuda to determine whether they were British subjects would be wrongheaded. Rather, as Toulmin tells us, the warrant is "implicit in the British Nationality Acts" (1958, p. 101), and to back it one would appeal "to the statutes governing the nationality of people born in the British colonies” (1958, p. 104).

With many philosophers, we recognize that evaluative properties, such as intrinsic goodness or badness, rightness or wrongness, virtuousness or unrighteousness, supervene upon other properties. For example, the badness of a given situation may be consequent upon the pain involved. Evaluative warrants then are of the sort

Given that $\quad x$ is pleasurable

We may take it that $x$ is intrinsically good

Given that $\quad x$ is an instance of promise keeping

We may take it that $x$ is a duty

Given that $\quad x$ practices belevolence

We may take it that $x$ is virtuous. ${ }^{2}$

May ampliative probability give an account of strength for Toulmin arguments with these various types of non-demonstrative warrants, and may it let us define and identify when strength is sufficient? We need first to give an account of ampliative probability.

\section{Cohen's Conception of Ampliative Support and Ampliative Probability}

In (1977), Cohen presents an account of ampliative support, referred to as inductive support, for empirical universally generalized conditional statements. A paradigm example might be 
Any colony of bees returns repeatedly to a blue colored food source.

To gain evidence for this statement, one designs a series of tests. The design is motivated by entertaining the hypothesis that discriminating the color blue explains why the bees return repeatedly to the source and seeking to rule out plausible alternative explanations. In test $t_{1}$, one simply notes bee behavior. Do bees return to a particular blue card which has been a food source? However, perhaps it is not the color of the food source, but its shade, relative position, or smell. (Compare Cohen 1977, p. 130.) There is some finite number of alternative hypotheses, which introduce relevant variables. The various shades or various relative positions of the card are values of the first two variables. Although there are infinitely many values of these two variables, experimenters will identify a finite number of ranges within which these values will fall and select a representative from each range. By contrast, smell of food might be regarded as a variable having just two values. Either there is smell of food on the card or there is not.

The series of variables gives rise to a series of cumulative increasingly complex tests. Assuming that shade, relative position, and smell of food are taken in that order, in test $t_{1}$, none of these variables are varied and the return of the bees to the card noted. In test $t_{2}$, the blue card is surrounded by other cards of differing shades of grey from black to white. The bees continue to return to the blue card. This shows that shade is not a causal factor, and the generalization has passed test $t_{2}$. In test $t_{3}$, both shade and relative position are varied. If the generalization holds for all tested combinations of values of these two variables, the generalization passes test $\mathrm{t}_{3}$. In test $\mathrm{t}_{4}$, experimenters may place a glass cover over the food to remove its smell. This variable is then varied in combination with the previous two. Should the bees continue to return to the blue card, the generalization has passed test $t_{4}$.

The number of tests which a generalization has passed determines its degree of inductive support. Where the number of tests is $n$ (and hence the number of variables deemed relevant is $\mathrm{n}-1$ ), degree of support may be understood as a function $\mathrm{s}[H, E]$, where $H$ is the universally generalized hypothesis being tested, $E$ is a body of evidence, the results of a series of canonical tests. $\mathrm{s}[H, E]$ maps into $\{0,1 / \mathrm{n}, \ldots, \mathrm{i} / \mathrm{n}, \ldots, \mathrm{n} / \mathrm{n}\}$. Let $E$ represent the total body of evidence generated by the $\mathrm{n}$ tests. If $H$ fails even test $\mathrm{t}_{1}, \mathrm{~s}[H, E]=0$. If $H$ passes $\mathrm{t}_{1}$, then $\mathrm{s}[H, E] \geq 1 / \mathrm{n}$. If $H$ passes $\mathrm{t}_{\mathrm{i}}$, then $\mathrm{s}[H, E] \geq \mathrm{i} / \mathrm{n}$. If $H$ passes $\mathrm{t}_{\mathrm{i}}$ but fails $\mathrm{t}_{\mathrm{i}+1}$, then $\mathrm{s}[H, E]=\mathrm{i} / \mathrm{n}$. If $H$ comes through all $\mathrm{n}$ tests without falsification, $\mathrm{s}[H, E]=\mathrm{n} / \mathrm{n}$.

If a hypothesis fails test $\mathrm{t}_{i}$, one may modify the hypothesis by adding to the antecedent the condition that the falsifying values of the relevant variable do not hold. For example, should height of the food source from the ground be a relevant variable and should the blue colored source of food be placed above a certain distance from the ground, say $m$ feet, bees will no longer return to it, then one could modify the hypothesis to read 
Any colony of bees returns repeatedly to a blue colored food source placed no more than $m$ feet above the ground.

The revised hypothesis will not be falsified by the test varying relative position.

We thus have a definition of inductive support as a binary relation holding between a generalization and a body of evidence. Cohen points out that to be genuine, tests results are "always replicable, within appropriate limits of precision" (1977, p. 133). Hence, if $E$ is genuinely, positively to support $H$, " $E$ must also state grounds for inferring the replicability of the results it reports" (1977, p. 134). E contains reports of the tests $t_{1}, \ldots, t_{i}, i \leq n$, where $n-1$ is the number of relevant variables. At each test $\mathrm{t}_{\mathrm{i}}$, only the variables up to i- 1 are varied and $E$ reports only about the results of those variations. $E$ is implicitly saying that none of the variables $\mathrm{v}_{\mathrm{i}}, \ldots, \mathrm{v}_{\mathrm{n}-1}$ were varied in test $\mathrm{t}_{\mathrm{i}}$. Hence, assuming $\mathrm{v}_{1}, \ldots, \mathrm{v}_{\mathrm{n}-1}$ is a complete list of the relevant variables,

The reported outcomes must have ensued solely as a result of the reported experimental circumstances and can be expected, so far as similar causes produce similar effects, to recur in the same circumstances, whenever all variants of other relevant variables are again absent. (Cohen 1977, p. 134)

Cohen sees evidential replicability as having two important implications. First, we may meaningfully introduce a unary support grading for a hypothesis $H$. From $\mathrm{s}[H, E] \geq \mathrm{i} / \mathrm{n}$, we may infer $\mathrm{s}[H] \geq \mathrm{i} / \mathrm{n}(1977, \mathrm{p} .134)$. We may refer to $\mathrm{s}[H]$ as the reliability of $H$. The inference is defeasible because there may have been mistakes in drawing up the list of relevant variables. The second implication is that even if $E$ ultimately falsifies $H$ at level $i+1$ but at no level previously, this does not mean that $\mathrm{s}[H, E]=0$ or that $\mathrm{s}[H]=0$. Rather $\mathrm{s}[H, E]=\mathrm{i} / \mathrm{n} . H$ has passed tests $\mathrm{t}_{1}, \ldots, \mathrm{t}_{\mathrm{i}}$ and must be given credit for that. The reliability of $H, \mathrm{~s}[H]=\mathrm{i} / \mathrm{n}$.

Given this concept of reliability, we may define a concept of inductive probability. ${ }^{3}$ Suppose $\mathrm{s}[(\forall x)(R x \rightarrow S x)]=\mathrm{i} / \mathrm{n}$. Consider the argument

$$
\therefore \frac{R \mathrm{a}}{\mathrm{Sa}}
$$

How probable, in the sense of ampliative or inductive probability being defined, is the conclusion given the premise, i.e. $\operatorname{Pr}_{\mathrm{A}}[\mathrm{Sa}, \mathrm{Ra}]$ ? It is also $\mathrm{i} / \mathrm{n}$. Thinking of probability, as Cohen does, as a grading of the soundness of an inference rule, the inductive probability of an inference rule will be the same as the reliability of the generalization corresponding to that rule. Cohen notes that as statements of inductive support are empirically defeasible, so are statements of inductive probability. In particular, such assessments may need to be significantly revised upon the discovery of new relevant variables.

Cohen has thus given us an answer for how strongly the premise of a certain type of non-demonstrative argument supports its conclusion. If the premise of the argument ascribes some property, relation, or condition to some particular or particulars and the conclusion ascribes some further property to these particulars, 
where the universally generalized conditional corresponding to the inference rule of the generalization is empirical, the strength of support is the same as the degree of inductive support for that generalized conditional given by a series of canonical tests designed with reference to the variables understood relevant to confirming or falsifying the generalization.

Clearly for empirical physical warrants as illustrated in our examples, the body of evidence determining the degree of ampliative probability constitutes the backing for the warrant, while the values of relevant variables constitute potential rebuttals. Cohen's analysis thus marks an advance over the simple statement of Toulmin's categories by indicating a canonical construction for the backing of (at least some) empirical warrants from which we may derive an objective answer to how strongly the premise or premises of the argument support the conclusion, based on our current knowledge of the relevant variables. This raises a significant question. As presented, Cohen's concept of ampliative probability applies to arguments with empirical physical warrants. Does ampliative probability have a wider application? In particular, may it apply to Toulmin arguments with personal, institutional, or evaluative warrants? Let us approach this question by first asking about Cohen's conception of the scope of ampliative probability in (1977).

\section{Ampliative Probability and the Toulmin Model}

On Cohen's view, the class of arguments whose strength can properly be appraised by ampliative probability consists of those arguments to whose warrants corresponds a generalization whose inductive support we may in some way assess. As our discussion suggests, Toulmin arguments with empirical physical warrants are the paradigm case of arguments whose strength can be meaningfully described as a degree of ampliative probability. Although our examples thus far have involved statements ascribing just monadic properties, this class of arguments clearly includes those with statements ascribing relations. Hence, arguments of the form

$$
\begin{aligned}
& \phi \mathrm{a}_{1}, \ldots, \mathrm{a}_{\mathrm{m}} \\
\therefore \psi & \psi \mathrm{a}_{1}, \ldots, \mathrm{a}_{\mathrm{m}}
\end{aligned}
$$

where $N \mathrm{a}_{1}, \ldots, \mathrm{a}_{\mathrm{m}}, R \mathrm{a}_{1}, \ldots, \mathrm{a}_{\mathrm{m}}$ are singular statements concerning physical matters of fact, are also arguments with empirical physical warrants. Corresponding to the warrants of such arguments are nomic universals (not just accidental generalizations) of the form

$$
\left(\forall x_{1}\right) \ldots\left(\forall x_{\mathrm{m}}\right)\left(\phi x_{1}, \ldots, x_{\mathrm{m}} \rightarrow \psi x_{1}, \ldots, x_{\mathrm{m}}\right) .
$$

Neither $N x_{1}, \ldots, x_{\mathrm{m}}$ nor $R x_{1}, \ldots, x_{\mathrm{m}}$ need be atomic predicates. Indeed, $N x_{1}, \ldots, x_{\mathrm{m}}$ could be a conjunction, where the conjuncts after the first indicate that some relevant variable at least some of whose values falsify an unqualified statement of universal connection does not have such values in this case. But such universals are supported by the series of canonical tests Cohen has used to characterize inductive support. 
Physical nomic universals may be appealed to as covering laws in causal explanations. But we may also have personal explanations, appealing in addition to the beliefs and desires of conscious agents. Such explanations also involve nomic universals, supporting what we called personal subjunctives in (2005a). Statements asserting a general connection between some overt observable behavior and some intention which explains it, such as

If a person were to strike a match, that person would intend for the match to light.

If a person were to put the car key into the ignition and turn it, that person would intend for the car to start.

are paradigm cases of personal subjunctives. As Cohen points out, humans accept a huge stock of such personal generalizations, using them in interpreting and making inferences about human behavior. Such generalizations are standardly not statable with exact precision and are not supported by experimental observational evidence controlled for relevant variables as with physical generalizations at least in scientific contexts. "The level of phenomena with which they deal is altogether too variegated and complex" (Cohen 1977, p. 247). Rather, such generalizations express our presumptions about what is normal or to be expected in human behavior, with the acknowledgment that there can be abnormal situations where these presumptions must be set aside. Such common sense presumptions can be learned from various sources and may be confirmed, up to a point, by observation of human behavior. They are thus empirical. That they are open to rebuttal in situations that are not normal makes them analogous to the physical universals which may be falsified given the operation of certain relevant variables. The condition of being in such an abnormal situation constitutes a relevant variable in the personal case. Normally, persons who strike matches intend for them to light, but not when they are demonstrating that matches cannot light in a vacuum. As with physical generalizations, these rebutting conditions are open to empirical observation.

There is a clear analogy between the physical and personal nomic generalizations corresponding to the empirical physical or personal warrants of Toulmin arguments. Observation that $\Phi$ 's are $\psi$ 's constitutes zeroth level of support for physical generalizations. Common sense understanding of motivation together perhaps with observation of behavior constitutes at least a basic level of support for personal generalizations. Observation of the effect or non-effect of various physical relevant variables can lead to a higher level of support or to a refined statement of the generalization. Consideration of special factors in a situation which might affect a person's motivation and observation to see the effects of these factors could lead to more strongly supported personal generalizations or generalizations refined to assert that the falsifying values of the relevant variables do not hold.

As with the arguments whose warrants correspond to physical generalizations, the arguments whose warrants correspond to personal generalizations are of the form 


$$
\therefore \frac{\phi x_{1}, \ldots, x_{\mathrm{m}}}{\psi x_{1}, \ldots, x_{\mathrm{m}}}
$$

where $\phi x_{1}, \ldots, x_{\mathrm{m}}, \psi x_{1}, \ldots, x_{\mathrm{m}}$ express properties or relations concerning overt human behavior or the intentions, motivations, or other dispositions underlying such properties. Here again, premise and conclusion are singular statements.

Corresponding to institutional warrants are nomic institutional generalizations, for example,

If a contract were signed by both parties, it would be valid.

If someone were born in Bermuda, he or she would be a British subject.

Since the evidence for such claims does not consist in observed confirming instances, to speak of such generalizations as supported to a certain degree through a series of canonical tests gathering experimental, observable evidence is not meaningful. However, we believe that the notion of ampliative probability can be extended to arguments with institutional warrants. A comprehensive discussion of this issue demands a separate inquiry. But we may indicate the strategy here. Suppose one questioned a legal generalization corresponding to a legal warrant. How might one argue for the generalization? As Cohen points out in (1970, pp. $157 \mathrm{ff}$ ), one could give an argument from legal precedent. This would involve first identifying the branch of law involved. That issue seems straightforward for our two examples. Cohen indicates that "Next we have to determine the legal variables that are relevant to this branch of law" (1970, p. 157). Variables relevant to whether a signatory to a contract was bound by its provisions include whether or not the person was under duress when he signed the contract or whether or not he was mentally competent. Variables relevant to citizenship include whether or not one has formally renounced that citizenship.

We can then, at least theoretically, define a series of canonical tests analogous to those presenting evidence for empirical generalizations based on experimental results. If a contract between two persons is valid, then both are bound by its provisions. If one defaults on his obligations, the other has good grounds for redress in the courts. Presumably, a suit might pass through courts at various levels, but in each instance there will be a highest court which has rendered a verdict. The evidence then consists of the records of these highest court decisions. If the decision went for the plaintiff in every case, then the generalization would be fully supported. If the decision went for the defendant, given certain values of a relevant variable, then the generalization would have less than full support. However, qualifying the generalization to rule out the disconfirming values of the relevant variables yields a more strongly supported generalization, and a stronger corresponding argument. Hence, an argument from the premises that both parties signed the contract and neither were under duress would be a stronger argument for the conclusion that the contract was valid than one where the sole premise was that both parties signed the contract. For both arguments with empirical warrants and arguments with institutional warrants, resistance to potential rebuttals indicates 
a stronger argument, a strength appropriately indicated by a degree of ampliative probability.

Likewise, evaluative warrants can be rebutted. That some experience is pleasurable is a prima facie reason to say that it is good. That one has promised to do $X$ is a prima facie reason to say that one ought to do $X$. But a pleasurable experience purchased at the expense of frustrating the legitimate interests of others is not good, nor is keeping a promise when some alternative action involves a weightier obligation. Given an evaluative generalization then and a recognized set of relevant variables, one can envision a series of canonical test cases, where individual situations are submitted to the test of conscience or moral sense. (Compare Cohen (1970), p. 174.) As with legal generalizations, evaluative generalizations qualified to indicate that certain values of relevant variables do not hold are more strongly supported than unqualified generalizations by this series of canonical tests of conscience. Likewise, arguments with evaluative warrants whose premises include assertions that rebutting conditions do not hold are stronger than arguments which do not, a strength which is also expressible through a higher degree of ampliative probability. Hence for each type of contingent warrant in our epistemic classification, the concept of ampliative probability applies to Toulmin arguments with such warrants. But how much ampliative strength is sufficient strength? What level of probability is necessary for ground adequacy? We turn to these questions in the next section.

\section{Ampliative Probability and Assessing Argument Strength}

Can we use Cohen's concept of ampliative probability to assess under what conditions premises are sufficiently strong so that their acceptability (should they be acceptable) is transferred to the conclusion? The question of degree of sufficiency or strength depends upon the context of the argument we are considering. This is obvious from judicial practice. In criminal cases, the prosecution must establish its case beyond a reasonable doubt. In civil cases, the plaintiff must establish his or her case on balance or preponderance of evidence. In (1977), Cohen shows how ampliative probability can be used in explicating both of these concepts. But let us begin by considering everyday contexts of argument, not those embedded in a formal legal proceeding.

Consider the argument

$$
\begin{aligned}
& a \text { ignited the fuse } \\
& \therefore a \text { intended to explode the bomb. }
\end{aligned}
$$

Certainly the warrant of this inference corresponds to a generalization presumed to hold typically, albeit not universally. Ordinarily when one ignites a fuse (connected to a bomb), one intends to explode the bomb. However, the warrant would be rebutted if we knew that the agent believed the bomb to be a fake, the fuse defective, or that the agent intended to douse the fuse with water before the flame could reach the bomb. But suppose we have no reason to believe that any of those 
rebuttals held in a's case. (This is not to say that we have evidence that they are not the case.) Then it would seem that if the premise were acceptable, so would be the conclusion.

Why is this argument sufficiently strong to justify our accepting the conclusion or regard the conclusion as a rational belief in light of the premise? Cohen presents the following rule of acceptance for rational belief for singular propositions based on singular premises:

For any singular proposition $\mathrm{S}$ about the individual or individuals $a_{1}, a_{2}, \ldots$, $a_{\mathrm{n}}$, accept $\mathrm{S}$ if and only if for some $\mathrm{R}$ you know that $\mathrm{R}$ states all the relevant evidence available about $a_{1}, a_{2}, \ldots, a_{\mathrm{n}}$ and that $\mathrm{p}_{\mathrm{I}}[\mathrm{S}, \mathrm{R}] \geq k{ }^{4}$

where $k$ has to be greater than zero but its more precise level is to be determined in accordance with the nature of the subject-matter and the best available list of relevant variables for tests on generalizations about the subject matter. (1977, p. 319)

Consider the premise. To be sure, if we had additional premises stating that a did not believe the bomb to be a fake, or the fuse defective, or that a did not intend to douse the fuse with water, we would have a stronger reason to accept the conclusion than if we had just the premise that a ignited the fuse. But in ordinary contexts, do we need this additional information to render the conclusion acceptable? Toulmin characterizes rebuttals as "conditions of exception" (1958, p. 101) and in their light, "the conclusion holds good "presumably" (1958, p. 101). In ordinary contexts, the burden of proof would be on the challenger to present evidence that any of these three conditions of rebuttal held. In ordinary contexts, there is not a mandate to make evidence countering such rebuttals available. Hence we may judge the premise as stating all the relevant evidence available.

What about the measure $k$ ? Can we justify that in ordinary contexts $\operatorname{Pr}_{\mathrm{A}}$ [a intended to explode the bomb, a ignited the fuse] ${ }^{3} k$, where $k$ satisfies the conditions of the criterion? I believe we can in this context, and that frequently we need not specify a list of relevant variables together with evidence that the generalization corresponding to the warrant is inductively supported to degree $k$. Where a generalization qualified by "usually" or "normally" states the way things are, there is a presumption for it which renders it acceptable. ${ }^{5}$ These generalizations describe the default situation and we may let $d$ indicate a level of support for such generalizations. But in the contexts we are discussing, $d$ will indicate the minimum level of inductive probability necessary to render the conclusion acceptable given the premises, i.e. $\operatorname{Pr}_{\mathrm{A}}[S, R]^{3} d$. We might define $d$ as the least level of support beyond which we are dealing with abnormal or exceptional relevant variables. If it is not a matter of common knowledge that a generalization describes the default situation, then we shall need ideally to resort to a series of cumulative tests on recognized (non-abnormal) relevant variables to verify that it does. The point is that common knowledge can certify that in ordinary circumstances the level of ampliative support and ampliative probability is $d$ independently of an overt series of canonical tests. Of course, should we have a best available list of relevant 
variables before us, should we see that variables $k+1$ and higher are exceptional, and that the generalization passes canonical tests through level $k$, we would again have that $\operatorname{Pr}_{\mathrm{A}}[S, R]^{3} k$. There are hence at least two ways to recognize that $\operatorname{Pr}_{\mathrm{A}}[S$, $R]^{3} k$.

Explicating the concepts of proof beyond reasonable doubt and proof on balance of evidence by means of ampliative probability is straightforward. Clearly, some contexts will demand a higher level of evidence than others. Although all things being equal, $\mathrm{S}$ may be acceptable on evidence R, some contexts, such as AngloAmerican criminal court proceedings, may require that we know that all things are equal, that our evidence R encompasses this information. For example, ordinarily

$a$ uttered a falsehood under oath

would be taken as sufficient reason for holding that

$a$ perjured himself.

But clearly there are excepting conditions which we may regard as the operation of relevant variables-a unknowingly uttered a falsehood, $a$ did not understand what he said, $a$ made his statement under duress. Let us assume that the listed conditions constitute a complete account of the relevant variables. Clearly then, as long as we have no information that one of these relevant variables constitutes a rebutting condition in this case, the more information we have that a relevant variable is favorable for applying the warrant-i.e, a knowingly-uttered a falsehood, understood what he said and the practice of taking oaths, and was not under duress - the stronger our argument.

Where $n$ is the total number of relevant variables in this case, $R_{1} x$ being the telling of an untruth under oath, $R_{2} x, \ldots, R_{\mathrm{n}} x$ being the conditions that relevant variables $R_{2}, \ldots, R_{\mathrm{n}}$ do not constitute rebuttals in this case, and $S x$ the condition that $x$ perjured himself, then the generalization

$$
(\forall x)\left(\left[R_{1} x \& R_{2} x \& \ldots \& R_{\mathrm{n}} x\right] \rightarrow S x\right)
$$

is fully supported. Consequently

$$
\operatorname{Pr}_{\mathrm{A}}\left[S \mathrm{a}, R_{1} \mathrm{a} \& R_{2} \mathrm{a}, \ldots, R_{\mathrm{n}} \mathrm{a}\right) \geq n / n .
$$

(Compare Cohen 1977, pp. 249-50.) By adding the information $R_{2} \mathrm{a}, \ldots, R_{\mathrm{n}}$ a to $R_{1} \mathrm{a}$, one removes all reasonable doubts in this case and the argument from $R_{1}$ a \& $R_{2}$ a, $\ldots, R_{\mathrm{n}}$ a to $S \mathrm{a}$ constitutes a proof beyond reasonable doubt. This is not to say that the argument is logically valid or that the corresponding generalization is logically true. It is logically possible that we have a Plantinga scenario here. An alien scientist from Alpha Centauri has captured $a$ and so altered his mind that he regards knowingly uttering a falsehood under oath to be a morally permissible act. But being a research subject of Alpha Centaurean scientists is not a relevant variable. Proof beyond reasonable doubt then is proof from premises that all recognized relevant variables in a given case are favorable or non-rebutting.

What may we say then of proof on balance or preponderance of evidence? Let us imagine a situation in which a proponent presents reasons for a conclusion and 
an opponent seeks to rebut his points by presenting reasons for the denial of the conclusion. We can imagine them proceeding in a point-counterpoint manner, although this need not be their actual procedure. Suppose the proponent presents a reason $R_{1}$ a for a conclusion $S \mathrm{a}$, where $\mathrm{s}\left[(\forall x)\left(R_{1} x \rightarrow S x\right)\right]=1 / n$, i.e., $\operatorname{Pr}_{\mathrm{A}}[S \mathrm{~S}$, $\left.R_{1} \mathrm{a}\right]=1 / n$. But suppose $R_{2}$ a constitutes a rebutting condition here, i.e., $\operatorname{Pr}_{\mathrm{A}}\left[\mathrm{Sa}, \mathrm{R}_{1} \mathrm{a}\right.$ $\left.\& R_{2} \mathrm{a}\right]=0$ and $\operatorname{Pr}_{\mathrm{A}}\left[\sim S \mathrm{a}, R_{1} \mathrm{a} \& R_{2} \mathrm{a}\right]=2 / n$. The challenger may answer by presenting another reason for $\mathrm{Sa}, R_{3}$. This in turn may be rebutted. If each of the proponent's reasons are rebutted by the challenger, then the proponent has failed to establish his case. On the other hand, if the challenger rebuts only some of the proponent's reasons, leaving others unrebutted, the proponent has shown his case on balance of evidence. He has presented more evidence for his conclusion than the challenger has presented for its denial. (Compare Cohen 1977, pp. 252-53.) The proponent would have shown his case on balance or preponderance of evidence, even though he had not shown that all relevant variables were favorable. The more considerations the proponent produces, the stronger the argument. "Decisions based on a greater total weight of evidence come out as being sounder, even if the actual truth of the matter is not beyond reasonable doubt" (Cohen 1977, p. 254). Ordinarily if both sides are allowed to present all available relevant evidence which they deem important, the jury will have sufficient evidence to decide the case where there is a reasonably high ampliative probability for their conclusion. (Compare Cohen 1977 , p. 254.) Hence, the notion of ampliative probability allows explication-at least for the class of Toulmin arguments we have identified-of standards of proof which are less than demonstrative, i.e., deductively valid, but which give us objective reason for accepting a conclusion in light of the acceptability of the premises.

We have shown for Toulmin arguments with warrants which can in principle be backed by evidence generated through canonical tests that Cohen's notion of ampliative support and ampliative probability may be applied to determine the degree of strength with which the premise supports the conclusion, and whether that degree is sufficient to render the conclusion acceptable in light of the premise. Our discussion leaves many open questions. We have not discussed how relevant variables are ordered or how one could bring about agreement on their proper ordering, and the effect ordering could have on determining argument weight. We must leave these issues to a further inquiry. ${ }^{6}$

We have implicitly assumed that if a warrant does not hold universally, but only typically or generally, that some rebutting conditions require us to set the warrant aside in certain instances. However, Toulmin in (1958) does not seem to require that less than necessary warrants be always accompanied by rebuttals. "[Other warrants] authorize us to make the step from data to conclusion either tentatively, or else subject to conditions, exceptions, qualifications" (1958, p. 100, italics added). Again, it is possible that "a warrant can be supported by pointing to a general correlation only, and not to an absolutely invariable one" (1958, p. 102). Suppose 
that our initial observation of bee behavior, canonical test $t_{1}$, indicated that only 90 percent of the time bees returned to a blue colored food source. One might reply that some yet to be identified relevant variable was operative here in 10 percent of the cases. Identify and remove that variable. Then observe bee behavior in a corrected test $\mathrm{t}_{1}$. This approach in effect accepts the dictum Cohen endorses, "Same cause, same effect." (See 1970, p. 172; 1977, pp. 170-172.) But does one want to build this assertion into the very understanding of non-demonstrative warrant and the nomic generalization corresponding to it? Corresponding to certain warrants could there simply be statistical nomic generalizations? If so, the class of Toulmin arguments we have delimited in the paper would be a limiting case of a wider class of Toulmin arguments assessing whose strength would involve additional considerations.

Finally, we have already indicated that not every argument is an instance of the Toulmin model. In (1992), Kienpointner presents a typology of arguments where he distinguishes warrant-using from warrant-establishing arguments, and these from arguments by analogy and by authority. (See 1992, p. 182.) If the premises of a warrant-establishing argument presented the data of some series of canonical tests, the strength of the argument would apparently be the same as the degree of inductive support. May this be generalized? To what extent may the strength of arguments not in the warrant-using class be appraised through ampliative considerations? These again are questions for further inquiry. To the extent that we have shown here that ampliative probability can be used to define and assess the strength of Toulmin arguments, we have begun an account of argument strength and ground adequacy for non-demonstrative arguments. ${ }^{7}$

\section{Notes}

1 As we argued in (1991), Toulmin regards universal generalizations of the form "All A are B" as either presenting statistical reports about a finite class of objects or as warrants, and thus strictly speaking inference rules and not statements, not able to stand in either data or claim positions in arguments. However, this view involves significant problems, as we show in (1991), pp. 56-61. 2. Here we are taking ' $x$ is intrinsically good,' ' $x$ is a duty,' ' $x$ is virtuous' to ascribe these properties outright or absolutely, as opposed to ascribing prima facie goodness, obligation, or virtue.

3. For Cohen's argument that this concept, which fails to satisfy both the Pascalian principles for negation and conjunction, rightfully deserves to be called a concept of probability, see (1977), pp. 199-200 and the sections referred to there.

4. I.e., $\operatorname{Pr}_{\mathrm{A}}[\mathrm{S}, \mathrm{R}] \geq k$.

5. For our discussion of the connection between acceptability and presumption, see (2005a), Chapter 2, especially pp. 21-30. For presumption for the normal, see Perelman and OlbrechtsTyteca (1969), p. 70.

6. Cohen addresses these issues in (1977, pp. 140-142).

7. We want to thank two anonymous referees of Informal Logic for comments which have allowed us to greatly improve an earlier version of this paper. 


\section{References}

Cohen, L.J. (1970). The Implications of Induction. London: Methuen \& Co. Ltd.

Cohen, L.J. (1977). The Probable and the Provable. Oxford: Clarendon Press.

Cohen, L.J. (1989). An Introduction to the Philosophy of Induction and Probability. Oxford: Clarendon Press.

Freeman, J.B. (1991). Dialectics and the Macrostructure of Arguments: A Theory of Argument Structure. Berlin and New York: Foris Publications.

Freeman, J.B. (2005a). Acceptable Premises: An Epistemic Approach to an Informal Logic Problem. Cambridge: Cambridge University Press.

Freeman, J.B. (2005b). "Systematizing Toulmin's Warrants: An Epistemic Approach." Argumentation 19, pp. 331-346.

Govier, T. (1987). Problems in Argument Analysis and Evaluation. Dordrecht/Providence: Foris Publications.

Kienpointner, M. (1992). "How to Classify Arguments." In F.H. van Eemeren, R. Grootendorst, J.A. Blair, C.A. Willard (eds.) Argumentation Illuminated. (pp. 178188). Amsterdam: SICSAT.

Perelman, C. \& L. Olbrechts-Tyteca. (1969). The New Rhetoric: A Treatise on Argumentation. Notre Dame and London: University of Notre Dame Press.

Plantinga, A. (1993). Warrant and Proper Function. Oxford: Oxford University Press.

Searle, J.R. (1969). Speech Acts: An Essay in the Philosophy of Language. Cambridge: Cambridge University Press.

Skyrms, B. (2000). Choice and Chance: An Introduction to Inductive Logic, Fourth Edition. Belmont,CA: Wadsworth/Thomson Learning.

Toulmin, S.E. (1958). The Uses of Argument. Cambridge: Cambridge University Press.

James B. Freeman Department of Philosophy Hunter College of The City University of New York 1413 HW, 695 Park Ave.

New York, NY 10021

jfreeman@hunter.cuny.edu 